\title{
Curvas de permanência de qualidade da água como subsídio para o enquadramento de corpos d'água a partir de modelagem matemática em regime não permanente
}

\section{Frequency curves for water quality as support for the framework of water bodies from mathematical modeling under unsteady regime}

\author{
Danieli Mara Ferreira ${ }^{1}$, Cristovão Vicente Scapulatempo Fernandes ${ }^{1}$ e Eloy Kaviski ${ }^{1}$ \\ ${ }^{1}$ Universidade Federal do Paraná, Curitiba, PR, Brasil \\ E-mails: danielimaraferreira@gmail.com (DMF), cvs.fernandes@gmail.com (CVSF), eloy.dhs@ufpr.br (EK)
}

Recebido: Setembro 17, 2015 - Revisado: Fevereiro 22, 2016 - Aceito: Março 18, 2016

\begin{abstract}
RESUMO
Modelos matemáticos de qualidade de água têm sido utilizados como ferramentas para o planejamento e a gestão de recursos hídricos em diversos países. Em geral, em rios, as análises são baseadas em simulações considerando condições de escoamento de regime permanente. Entretanto, bacias urbanas apresentam uma intensa dinâmica, consequente de mecanismos de uso e ocupação do solo, capaz de induzir processos de poluição que requerem uma análise que contemple aspectos físicos, químicos e biológicos. A abordagem em estado não-permanente permite descrever de forma mais realista estas características, e associar de maneira consistente as interações de qualidade e quantidade de água, em função da representação hidrodinâmica de um sistema. Esta pesquisa contribui para esse entendimento usando como estudo de caso o rio Iguaçu, localizado na região metropolitana de Curitiba, ao analisar potenciais impactos de avaliações de qualidade baseadas em uma comparação de condições de estado permanente e não-permanente como forma de subsidiar elementos para a gestão do uso da água. O modelo aqui proposto (SIHQUAL), desenvolvido em módulos tradicionais, utiliza métodos de diferenças finitas explícitas para solução das equações de Saint-Venant integradas com a equação de transporte de massa, para demanda bioquímica de oxigênio (DBO) e oxigênio dissolvido (OD). Para a análise de qualidade da água utilizou-se do conceito de curva de permanência de qualidade da água. Observou-se principalmente que modelos em estado transiente oferecem maior flexibilidade e uma distinta perspectiva para o gerenciamento, em especial quanto à aplicação dos instrumentos de gestão de recursos hídricos, como o enquadramento.
\end{abstract}

Palavras-chave: Modelo de qualidade de água; Equações de Saint-Venant; Gestão de recursos hídricos; Rio Iguaçu.

\begin{abstract}
Water quality models have been used as tools for planning and water resources management in many countries. Generally, in rivers the simulations are based on flow conditions under steady regime. However, urbanized basins have an intense dynamics, the consequence of land use and soil occupation mechanisms, able to induce pollution processes that require representation of physical, chemical and biological processes. The unsteady regime approach provides a better description of these characteristics, and a more consistent association of water quality and quantity interactions, based on a hydrodynamic representation of the system. This paper aims to contribute to this understanding using as case study the Iguaçu river, located in the metropolitan region of Curitiba, analyzing possible impacts of quality evaluations based on an analogy between steady and unsteady regime conditions as a manner of supporting water management elements. The proposed model (SIHQUAL), developed in traditional modules, uses explicit finite difference methods to solve the Saint-Venant equations integrated with the mass transport equation, for biochemical oxygen demand (BOD) and dissolved oxygen (DO) concentrations. The frequency curve concept was used to analyze the water quality. It was observed mainly that water quality models under unsteady state offer more flexibility and a different perspective for management, especially regarding the implementation of water resources management instruments, like the framework.
\end{abstract}

Keywords: Water quality model; Saint-Venant equations; Water resources management; Iguaçu river. 
Curvas de permanência de qualidade da água como subsídio para o enquadramento de corpos d'água a partir de modelagem matemática em regime não permanente

\section{INTRODUÇÃO}

A necessidade de compreender e prever o comportamento de corpos aquáticos do ponto de vista físico, químico e biológico é de fundamental relevância para a engenharia de recursos hídricos. Tal conhecimento permite estabelecer elementos para a gestão da água de modo a assegurar quantidade e qualidade a seus propósitos. Para a consecução destes objetivos de integração, a utilização de modelos matemáticos se consolidou como uma estratégia metodológica comum em diversos estudos (BEDRI et al., 2014; BOYE; FALCONER; AKANDE; 2015; HARTNETT; NASH, 2015; LI et al., 2015).

Base para esses modelos, a equação de transporte de massa de um escalar fornece uma estimativa da variação da distribuição de uma determinada substância ao longo dos sistemas, incorporando mecanismos de advecção, dispersão e reação. No contexto da implementação dos instrumentos de gestão de recursos hídricos - definidos na Lei n ${ }^{\circ}$ 9.433/97 (BRASIL, 1997) -, essa expressão usualmente tem sido solucionada com a hipótese de regime permanente (estacionário), em que a variação temporal da vazão e da concentração não é considerada. Nestes casos, são utilizados procedimentos aproximados para estimativa das características hidráulicas do canal, comumente através de coeficientes de descarga ou pela equação de Manning (KNAPIK et al., 2009; PARMAR; KESHARI, 2012; BABBAR, 2014). Os modelos Qual2E e Qual2K são exemplos típicos de algoritmos com essas características.

No que concerne ao comportamento hidrológico, em condições críticas, como em períodos de estiagem, a suposição de estado permanente normalmente é válida, pois a variação dos componentes do escoamento em relação ao tempo é muito gradual. Entretanto, em ambientes urbanos, onde o lançamento de cargas poluidoras é contínuo, a modelagem de qualidade de água em estado estacionário pode levar a resultados imprecisos (GARCIA; TUCCI, 2000). Para Dortch e Johnson (1992), simulações em regime permanente geram resultados satisfatórios porque os efeitos dos processos cinéticos sobre a concentração podem sobrepor os efeitos do transporte em alguns casos. No entanto, o impacto da hidrodinâmica de um rio na qualidade da água, dentro deste contexto, ainda não foi descrito na literatura.

Deste modo, somente uma análise criteriosa sobre o transporte pode inferir sua real importância acerca da distribuição de massa no sistema. Nesse âmbito, os modelos hidrodinâmicos associados aos de qualidade de água oferecem maior precisão aos resultados pretendidos, e podem auxiliar a análise da incerteza associada aos parâmetros de reação, usualmente utilizados na calibração de modelos de qualidade de água.

Os trabalhos de Larentis, Collischonn e Tucci (2008), Sorribas et al. (2012) e Fan, Collischonn e Rigo (2013) tem realizado esforços para melhorar as representações hidrológica e hidrodinâmica em grandes bacias, incluindo análises dos efeitos sobre a qualidade da água, e examinando principalmente cenário futuros. Nesse sentido, um importante aspecto da abordagem não-permanente como ferramenta na gestão de recursos hídricos é a possibilidade de integração entre os aspectos de quantidade e qualidade de água. Tal análise é compilada através do conceito da curva de permanência, que permite a associação de concentrações a vazões (BRITES, 2010). Assim, relaciona-se a distribuição do poluente a uma probabilidade de ocorrência, indicando o percentual de tempo em que esta concentração é igualada ou superada pelo menos uma vez ao longo do tempo.

A principal contribuição desta pesquisa está na proposição de curvas de permanência com a finalidade de garantir flexibilidade ao enquadramento, ou verificar a frequência de transgressão de limites, em condições de uma integração com a dinâmica de vazões em regime não permanente, não relatada em estudos semelhantes. A partir da relação quantidade-qualidade é possível inferir, ainda, quais os períodos e locais críticos, definindo um planejamento adaptável para retiradas de água e lançamento de efluentes ao longo do ano. Do mesmo modo, em trechos ou ocasiões de maior demanda, regula-se a cobrança pelo uso da água.

Essa abordagem foi utilizada por Porto et al. (2007) e Brites (2010), que associaram concentrações a vazões observadas no rio Iguaçu através de dados de monitoramento e simulação de qualidade da água em condição permanente. Outros estudos têm produzido essas curvas com dados de qualidade da água em rios (OLIVEIRA et al., 2011; CUNHA; CALIJURI; MENDIONDO, 2012) e reservatórios (CUNHA et al., 2011). Alguns trabalhos ainda avaliaram o risco percentual de incompatibilidade dos resultados de monitoramento com padrões de qualidade (ZHANG; ARHONDITSIS, 2008; CUNHA; CALIJURI, 2010).

Essas pesquisas têm chamado atenção à necessidade de análises de risco para a gestão hídrica, ao invés de fundamentar ações em associações entre concentração e vazões de referência, como definido pela Resolução CONAMA (BRASIL, 2005). Ainda, esses trabalhos têm sido realizados, em geral, a partir de dados de monitoramento, com aplicações do ponto de vista da modelagem ainda pouco exploradas.

Embora comuns no Brasil, planos de monitoramento dificilmente transformam os resultados em elementos que orientam políticas públicas para a recuperação de sistemas aquáticos. Nesse contexto, a utilização de modelos matemáticos surge como alternativa para a criação de uma base para definição de metas graduais para melhoria da qualidade, através de previsão de cenários (planos de despoluição), e extrapolação e interpolação de dados, por exemplo. A abordagem em regime não-permanente, em especial, tem o potencial de prever o comportamento do sistema ao longo do tempo e do espaço.

Nesta pesquisa são apresentadas simulações para os parâmetros demanda bioquímica de oxigênio (DBO) e oxigênio dissolvido (OD) no rio Iguaçu, que drena Curitiba e região metropolitana (PR). Essas são duas das principais variáveis de qualidade usualmente analisadas em casos de rios que recebem efluentes industriais e domésticos, e que são reguladas pela legislação em diversos países.

O modelo apresentado, implementado no software $\mathrm{Matlab}^{\circledR} \mathrm{e}$ denominado SIHQUAL (Simulação Hidrodinâmica e de Qualidade da Água), resolve as equações de Saint-Venant e de qualidade da água através da associação de métodos de diferenças finitas explícitas. Ainda, em uma etapa intermediária são realizadas simulações de qualidade em estado estacionário. A partir dos resultados de concentração em regime permanente e não-permanente, são construídas curvas de permanência para qualidade, e comparadas as diferenças entre as duas abordagens em termos de aplicações para o planejamento e a Gestão de Recursos Hídricos. 


\section{BACIA DO ALTO RIO IGUAÇU}

A bacia do Alto Iguaçu concentra cerca de $30 \%$ da população urbana do estado do Paraná, e representa um caso típico de muitas cidades, onde o processo de ocupação irregular de várzeas e áreas de mananciais, além de coleta e tratamento de efluentes insuficientes, comprometam a qualidade da água e geram problemas para os sistemas de abastecimento de água, de tratamento de efluentes e de drenagem urbana (FERNANDES, 2013).

Inserido na bacia do Alto Iguaçu, o rio Iguaçu nasce na Serra do Mar e estende-se por aproximadamente $90 \mathrm{~km}$ até o limite da região metropolitana de Curitiba (PR), com uma área de drenagem de $3.000 \mathrm{~km}^{2}$. Na Figura 1 são identificados pontos de monitoramento no trecho do rio estudado $(83,5 \mathrm{~km})$. As seções IG2, IG3 e IG4, localizadas na área de ocupação urbana, recebem significativos aportes de efluentes domésticos e industriais, além de contribuições por escoamento superficial. Os pontos IG5 e IG6, por sua vez, drenam uma região agrícola e recebem vazões de tributários menos impactados que o trecho a montante.

Essa bacia tem sido objeto de diversas pesquisas relacionadas à qualidade da água (ALMEIDA et al., 2013; COELHO, 2013; KNAPIK, 2014). No entanto, apesar dos avanços no entendimento da dinâmica desse sistema, tais estudos destacam a importância de integrar os conceitos quali-quantitativos em bacias críticas, de modo a gerar informações que auxiliem a calibração de modelos, as estratégias de monitoramento e a avaliação dos dados. Nesta pesquisa são propostas novas contribuições baseadas em análises de qualidade da água em condições de regime não-permanente, cujos impacto ainda não foram avaliados para a bacia em destaque.
A partir de dados de vazão e geometria das seções transversais do rio são resolvidas as equações de Saint-Venant, que fornecem as velocidades na direção longitudinal e a área de escoamento. Posteriormente esses resultados são utilizados no módulo de qualidade de água, com dados de monitoramento obtidos entre os anos de 2005 e 2013.

\section{MODELOS HIDRODINÂMICO E DE QUALIDADE}

Assim como em modelos semelhantes de qualidade de água, o SIHQUAL, de domínio público (FERREIRA, 2015), é formado por três módulos principais: (i) simulação das velocidades e profundidades ao longo do canal, (ii) solução da equação de advecção-dispersão-reação, e (iii) análise aplicada à gestão de recursos hídricos. Na Figura 2 é apresentado o fluxograma representando essa concepção.

A simulação em duas fases é possível porque se considera que a substância estudada não afeta o escoamento ou as propriedades do fluido. Após a aplicação dos módulos (i) e (ii), são construídas as curvas de permanência para qualidade de água.

O modelo hidrodinâmico unidimensional (1D) é formado pelas equações de conservação de massa e de quantidade de movimento (equações de Saint-Venant) (Equações 1 e 2), enquanto o modelo de qualidade de água baseia-se na solução da equação de transporte com advecção-dispersão-reação (Equação 3):

$B \frac{\partial y}{\partial t}+U B \frac{\partial y}{\partial x}+A \frac{\partial U}{\partial x}+U \frac{\partial A}{\partial x}=q$

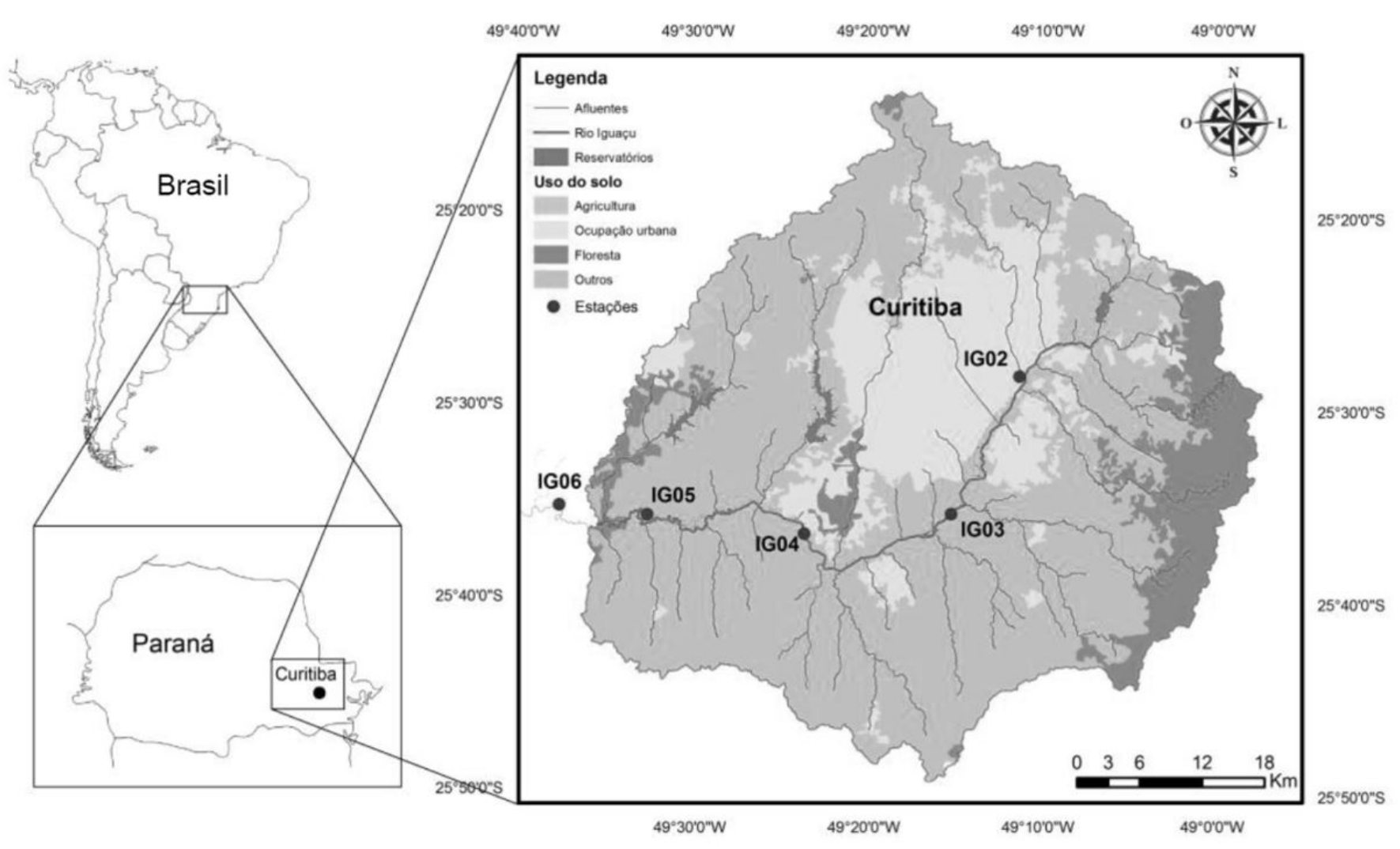

Figura 1. Localização dos pontos de monitoramento no rio Iguaçu. Fonte: Knapik (2014). 
Curvas de permanência de qualidade da água como subsídio para o enquadramento de corpos d’água a partir de modelagem matemática em regime não permanente

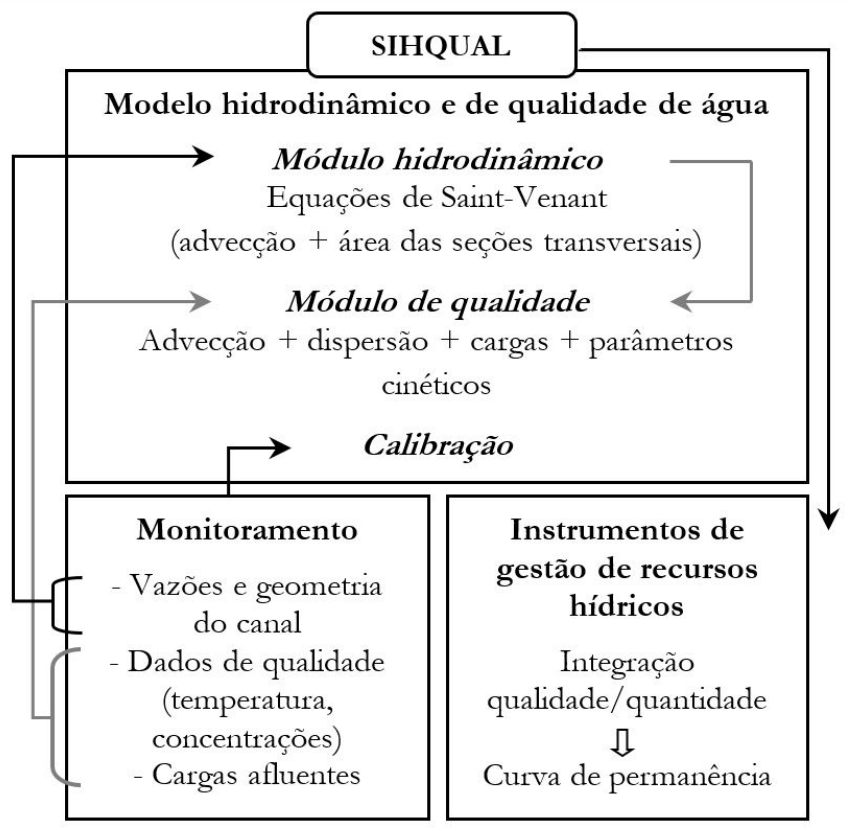

Figura 2. Síntese do desenvolvimento dos modelos hidrodinâmico e de qualidade de água.

$$
\begin{aligned}
& \frac{\partial U}{\partial t}+U \frac{\partial U}{\partial x}+g \frac{\partial y}{\partial x}=g\left(S_{0}-S_{f}\right) \\
& \frac{\partial C}{\partial t}+U \frac{\partial C}{\partial x}-\frac{D}{A} \frac{\partial A}{\partial x} \frac{\partial C}{\partial x}-D \frac{\partial^{2} C}{\partial x^{2}} \pm F=0
\end{aligned}
$$

onde $B$ representa a largura do topo da seção transversal (m), y é a profundidade do escoamento $(\mathrm{m}), U$ é a velocidade longitudinal do escoamento $\left(\mathrm{m} \cdot \mathrm{s}^{-1}\right), A$ é a área da seção transversal $\left(\mathrm{m}^{2}\right), q$ é a contribuição lateral por unidade de comprimento do canal $\left(\mathrm{m}^{3} \cdot \mathrm{s}^{-1} \cdot \mathrm{m}^{-1}\right), g$ é a aceleração da gravidade $\left(\mathrm{m} \cdot \mathrm{s}^{-2}\right), S_{0}$ é a declividade do fundo do canal $\left(\mathrm{m} . \mathrm{m}^{-1}\right)$ e $S$ refere-se à declividade da linha de energia $\left(\mathrm{m} \cdot \mathrm{m}^{-1}\right)$. Na Equação $3 C$ é a concentração média na seção transversal de uma determinada substância $\left(\mathrm{kg} \cdot \mathrm{m}^{-3}\right), D$ representa o coeficiente de dispersão longitudinal $\left(\mathrm{m}^{2} \cdot \mathrm{s}^{-1}\right)$, e $F$ é o termo para transformações de massa e cargas externas $\left(\mathrm{kg} \cdot \mathrm{m}^{-3} \cdot \mathrm{s}^{-1}\right)$.

As Equações 1 e 2 representam o escoamento não-permanente gradualmente variado em um canal de seção transversal irregular, com fluxo predominante na direção longitudinal e contribuições laterais. A Expressão 3, por sua vez, define o modelo de qualidade de água, e representa a distribuição de um constituinte na água (dada pela grandeza física concentração C). Essa equação faz um balanço entre as transferências de matéria através dos contornos e as transformações que ocorrem dentro de um sistema. $\mathrm{O}$ transporte de massa resulta dos processos de advecção e dispersão, enquanto as perdas ou ganhos advêm de processos químicos (reações químicas em geral), físicos (decantação de particulados, por exemplo) ou biológicos (como crescimento e morte de algas). A distribuição de uma determinada espécie no corpo hídrico ainda é alterada por meio de contribuições externas, pontuais ou difusas.

A resistência ao escoamento é causada pelo cisalhamento do fluido com as margens e fundo do canal, e pode ser estimada pelas leis de resistência análogas àquelas usadas para fluxo permanente
(MAHMOOD; YEVJEVICH, 1975). Logo, a equação de Manning é utilizada para avaliar a declividade da linha de energia $S_{f}$ :

$$
S_{f}=\left(n U / R_{H}{ }^{2 / 3}\right)^{2}
$$

onde $n$ representa o coeficiente de rugosidade de Manning $\left(\mathrm{m}^{-1 / 3} \cdot \mathrm{s}\right)$ e $R_{H}$ é raio hidráulico (m).

Para os parâmetros DBO e OD, o termo F na Expressão 3 é dado por (BROWN; BARNWELL, 1987):

$$
\begin{aligned}
& F_{D B O}=-\left(K_{d}+K_{s}\right) C_{D B O}+\text { cargas } \\
& F_{O D}=K_{a}\left(O_{s}+C_{O D}\right)-K_{d} C_{D B O}-K_{4} / H-\alpha_{5} \beta_{1} N_{1}-\alpha_{6} \beta_{2} N_{2}
\end{aligned}
$$

onde $C_{D B O}$ é a concentração de $\mathrm{DBO}, K_{d}$ representa o coeficiente de taxa de desoxigenação $\left(\mathrm{d}^{-1}\right)$ e $K$ é o coeficiente de remoção de DBO pela sedimentação $\left(\mathrm{d}^{-1}\right) ; K_{a}$ é o coeficiente de reaeração $\left(\mathrm{d}^{-1}\right), C_{O D}$ é a concentração de $\mathrm{OD}, O_{s}$ representa a concentração de saturação de oxigênio dissolvido $\left(\mathrm{mgO}_{2} \cdot \mathrm{L}^{-1}\right), K_{4}$ é a taxa de demanda de oxigênio pelo sedimento $\left(\mathrm{gO}_{2} \cdot \mathrm{m}^{-2} \cdot \mathrm{d}^{-1}\right), H$ é a profundidade média do canal (m); o termo $\alpha_{5}$ representa a taxa de oxigênio consumido por cada unidade de amônia oxidada $\left(\mathrm{mgO}_{2} \cdot \mathrm{mgN}^{-1}\right)$, $\alpha_{6}$ é taxa de oxigênio consumido por cada unidade de nitrito oxidado $\left(\mathrm{mgO}_{2} \cdot \mathrm{mgN}^{-1}\right), \beta_{1}$ é a taxa de oxidação da amônia $\left(\mathrm{d}^{-1}\right)$, $\beta_{2}$ é a taxa de oxidação do nitrito $\left(\mathrm{d}^{-1}\right), N_{1}$ é a concentração de amônia (mgN.L $\left.{ }^{-1}\right)$ e $N_{2}$ define a concentração de nitrito $\left(\mathrm{mgN} . \mathrm{L}^{-1}\right)$.

O coeficiente $K_{d}$ na Equação 5 incorpora a decomposição da matéria orgânica pela biomassa suspensa na massa líquida e no lodo de fundo. A transformação da matéria pelas bactérias aderidas ao lodo depende da área de exposição e, portanto, em sistemas rasos, o valor de $K_{d}$ tende a ser maior do que em rios profundos. Esse coeficiente é influenciado principalmente por: temperatura, características da matéria orgânica, e presença de substâncias inibidoras no sistema.

O coeficiente $K_{s}$, por sua vez, está relacionado à remoção da matéria orgânica da coluna d'água por sedimentação. Em corpos hídricos rasos, onde há lançamento de efluentes, os efeitos da sedimentação podem ser significativos, uma vez que nessas regiões há uma maior facilidade de ocorrência da sedimentação (CHAPRA, 1997).

O material em suspensão presente na água pode sedimentar em determinados trechos, formando uma camada de logo no fundo do curso d'água. Além da matéria originada de efluentes, folhas e plantas aquáticas, esses depósitos são constituídos por uma biota específica, que contribuem para o consumo de OD no corpo hídrico, representado pelo parâmetro $K_{4}$. A taxa de deposição pode variar de acordo com a vazão: em períodos de estiagem, a deposição de sólidos é favorecida, enquanto em cheias o material pode ser removido ou transportado para outro trecho do sistema.

O processo de reaeração, que tem um importante papel na simulação de OD, consiste na troca de oxigênio na interface ar-água, e sofre interferência principalmente das características hidráulicas do canal, da presença de surfactantes e partículas suspensas, da ação do vento e da temperatura da água (BOWIE; MILLS; PORCELLA, 1985).

Em modelos de qualidade de água, o coeficiente $K_{a}$ usualmente é determinado através de fórmulas (conceituais e empíricas), valores médios tabelados ou estimativas relacionadas com a vazão do corpo hídrico. Nesta pesquisa, a equação de 
O'Connor e Dobbins, baseada na profundidade e na velocidade do canal, é utilizada para determinar $K_{a}$ :

$K_{a}=3,95 U^{0,5} / H^{1,5}$

\section{Soluções numéricas}

Devido ao comportamento numérico distinto das equações, e a diferenças de magnitude dos diversos termos envolvidos, Atkinson et al. (1998) sugerem que diferentes esquemas de solução podem ser mais apropriados para um modelo em relação ao outro. Esta foi a abordagem adotada neste trabalho, assim como em outros estudos semelhantes (MANNINA; VIVIANI, 2010; ROCHA; PITOMBEIRA, 2013). O método difusivo de Lax foi aplicado para a solução das equações de Saint-Venant, enquanto o módulo de transporte foi resolvido pelo método FTCS (ForwardTime/Centered-Space). O primeiro fornece soluções estáveis e convergentes para o modelo hidrodinâmico, como comprovado por Patowary e Sarma (2013), ao passo que o esquema FTCS tem sido aplicado com sucesso principalmente na comparação de soluções numéricas e analíticas da equação de advecção-dispersão-reação (NAJAFI, 2008).

Os intervalos espacial e temporal de simulação foram $\Delta \mathrm{x}=500 \mathrm{~m} \mathrm{e} \Delta \mathrm{t}=50 \mathrm{~s}$, respectivamente, atendendo aos critérios de estabilidade dos métodos, definidos nos itens a seguir. Os algoritmos de solução das equações envolvidas estão disponíveis em Ferreira (2015).

\section{Módulo hidrodinâmico}

O esquema difusivo de Lax constitui um método de diferenças finitas explícitas e de simples aplicação, com acurácia de primeira ordem no tempo e segunda ordem no espaço (TANNEHILL; ANDERSON; PLETCHER, 1997). Essa técnica aproxima as derivadas parciais temporais e espaciais pelas seguintes representações (MAHMOOD; YEVJEVICH, 1975):

$$
\begin{aligned}
& \partial f / \partial t=\left\{f_{i}^{k+1}-\left[\alpha f_{i}^{k}+(1-\alpha)\right] f^{*}\right\} / \Delta t \\
& f^{*}=\left(f_{i-1}^{k}+f_{i+1}^{k}\right) / 2 \\
& \partial f / \partial x=\left(f_{i+1}^{k}-f_{i-1}^{k}\right) / 2 \Delta x
\end{aligned}
$$

onde $f$ representa a variável dependente, e $\alpha$ é uma constante; $\Delta \mathrm{x}$ e $\Delta \mathrm{t}$ definem o intervalo de discretização espacial e temporal, respectivamente. Mahmood e Yevjevich (1975) sugerem um valor de 0,1 para o coeficiente $\alpha$, para que haja suavização de resultados com oscilações. A estabilidade do método está sujeita à condição de Courant:

$$
\Delta t / \Delta x \leq 1 /|U+c|
$$

onde $c$ é a celeridade $\left(\mathrm{m} \cdot \mathrm{s}^{-1}\right)$.

Aplicando o método difusivo de Lax à equação para continuidade, representada pela Equação 1, obtém-se uma expressão para a profundidade de água no canal:

$$
\begin{aligned}
& y_{i}^{k+1}=\alpha y_{i}^{k}+(1-\alpha) y^{*} \\
& -U^{*} \Delta t\left(y_{i+1}^{k}-y_{i-1}^{k}\right) / 2 \Delta x \\
& -U^{*} \Delta t\left(A_{i+1}^{k}-A_{i-1}^{k}\right) / B^{*} 2 \Delta x \\
& -A^{*} \Delta t\left(U_{i+1}^{k}-U_{i-1}^{k}\right) / B^{*} 2 \Delta x+q_{i}^{k} \Delta t / B^{*}
\end{aligned}
$$

Aplicando o mesmo à Equação 2, para conservação de momento, tem-se o cálculo da velocidade no instante $t_{k+1} \mathrm{com}$ base nos valores do tempo $t_{k}$ :

$$
\begin{aligned}
& U_{i}^{k+1}=\alpha y_{i}^{k}+(1-\alpha) U^{*} \\
& -U^{*} \Delta t\left(U_{i+1}^{k}-U_{i-1}^{k}\right) / 2 \Delta x \\
& -g \Delta t\left(y_{i+1}^{k}-y_{i-1}^{k}\right) / 2 \Delta x+g \Delta t\left(S_{0}-S_{f}^{*}\right)
\end{aligned}
$$

As condições iniciais requeridas para solução das Equações 12 e 13 são profundidade, velocidade e geometria do canal para o instante $t=0$ ao longo da direção longitudinal. As condições de contorno compreendem essas mesmas propriedades nas seções de montante e jusante, conhecidas em todo o período simulado. Assim, para solução do modelo hidrodinâmico foram necessários dados das seções transversais, hidrogramas e equações das curvas-chaves dos pontos monitoramento.

\section{Módulo de qualidade da água}

No método FTCS, a derivada temporal é aproximada por diferenças progressivas, e as derivadas espaciais são estimadas por diferenças centradas:

$\partial f / \partial t=f_{i}^{k+1}-f_{i}^{k} / \Delta t$

$\partial f / \partial x=f_{i+1}^{k}-f_{i-1}^{k} / 2 \Delta x$

$\partial^{2} f / \partial x^{2}=f_{i+1}^{k}-2 f_{i}^{k}+f_{i-1}^{k} /(\Delta x)^{2}$

Os requerimentos de estabilidade para solução da equação de advecção-dispersão são definidos por (CHAPRA, 1997):

$\lambda=D \Delta t /(\Delta x)^{2}<1 / 2$

$\gamma=U \Delta t / \Delta x<1$

em que $\lambda$ é o número de difusão e $\gamma$ é denominado número de Courant.

Ao aplicar o método FTCS a Equação 3, tem-se uma expressão explícita para cálculo da concentração:

$$
\begin{aligned}
& C_{i}^{k+1}=C_{i}^{k}-U_{i}^{k} \Delta t\left(C_{i+1}^{k}-C_{i-1}^{k}\right) / 2 \Delta x \\
& +\frac{D \Delta t}{A_{i}^{k}} \frac{A_{i+1}^{k}-A_{i-1}^{k}}{2 \Delta x} \frac{C_{i+1}^{k}-C_{i-1}^{k}}{2 \Delta x} \\
& +D \Delta t\left(C_{i+1}^{k}-2 C_{i}^{k}+C_{i-1}^{k}\right) /(\Delta x)^{2} \pm F \Delta t
\end{aligned}
$$


Curvas de permanência de qualidade da água como subsídio para o enquadramento de corpos d’água a partir de modelagem matemática em regime não permanente

Como condição inicial considerou-se a mediana das séries medidas em cada ponto de monitoramento. Nos trechos intermediários as concentrações foram obtidas através de interpolação linear. Para a definição da condição de contorno de montante foi estipulada uma relação hipotética entre concentração e vazão, uma vez que séries temporais de concentração não estão disponíveis. Considerou-se que os pares de concentração e vazão medidos são médias diárias e, através de interpolação do tipo PCHIP (Piecewise Cubic Hermite Interpolating Polynomial) (FRITSCH; CARLSON, 1978), com as vazões observadas obteve-se as concentrações correspondentes. Deste modo, foi definida uma série contínua de concentração em função do tempo na seção de montante. Utilizou-se os dados medidos de 2005 a 2013 (de 26 a 40 pares vazão-concentração, variando com o ponto de monitoramento), supondo que abrangem as faixas de variação de concentração e vazão que ocorrem naturalmente ao longo de um ano. No ponto de jusante considerou-se que as concentrações sejam iguais as da seção anterior simulada.

Finalmente, para solução do modelo de qualidade de água em regime permanente foi aplicado o método de diferenças finitas com representação em diferenças centradas a Equação 3, sem o termo $\partial C / \partial t$. Para DBO e OD obtém-se, respectivamente:

$$
\begin{aligned}
& {\left[-\frac{U_{i}}{2 \Delta x}+\frac{D}{A_{i} 2 \Delta x} \frac{A_{i+1}-A_{i-1}}{2 \Delta x}-\frac{D}{(\Delta x)^{2}}\right] C_{i-1}} \\
& +\left[\frac{2 D}{(\Delta x)^{2}}+\left(K_{d}+K_{s}\right)\right] C_{i} \\
& +\left[\frac{U_{i}}{2 \Delta x}-\frac{D}{A_{i} 2 \Delta x} \frac{A_{i+1}-A_{i-1}}{2 \Delta x}-\frac{D}{(\Delta x)^{2}}\right] C_{i+1}=\text { cargas }
\end{aligned}
$$

$$
\begin{aligned}
& {\left[-\frac{U_{i}}{2 \Delta x}+\frac{D}{A_{i} 2 \Delta x} \frac{A_{i+1}-A_{i-1}}{2 \Delta x}-\frac{D}{(\Delta x)^{2}}\right] C_{i-1}} \\
& +\left[\frac{2 D}{(\Delta x)^{2}}+K_{a}\right] C_{i} \\
& +\left[\frac{U_{i}}{2 \Delta x}-\frac{D}{A_{i} 2 \Delta x} \frac{A_{i+1}-A_{i-1}}{2 \Delta x}-\frac{D}{(\Delta x)^{2}}\right] C_{i+1} \\
& =\left[K_{a} O_{s}-K_{d} C_{D B O}-K_{4} / H-\alpha_{5} \beta_{I} N_{1}-\alpha_{6} \beta_{2} N_{2}\right]
\end{aligned}
$$

As Equações 20 e 21 resultam em um sistema de equações lineares, resolvido através do método do algoritmo de Thomas. Para a condição de contorno de jusante adotou-se a mediana dos valores medidos de concentração nesse ponto. Na condição de montante considerou-se fluxo de concentração nulo $(d C / d x=0)$. Para o modelo de qualidade de água em regime permanente, o intervalo de discretização espacial utilizado foi de $25 \mathrm{~m}$, valor suficiente para atender às condições de convergência do método, que determina que a matriz gerada deva ser diagonalmente dominante (HIRSCH, 1991).

\section{RESULTADOS E DISCUSSÃO}

\section{Modelagem hidrodinâmica}

No módulo hidrodinâmico, o procedimento de solução consiste em determinar o hidrograma em um ponto do rio a partir do hidrograma conhecido em uma seção de montante. Deste modo, obtêm-se as variações de velocidade e área ao longo do tempo e do espaço.

O ano de 2010 foi utilizado nas simulações, uma vez que possui disponibilidade de séries de vazão observadas. A avaliação de um ano completo permite representar as mudanças sazonais e o balanço de massa no sistema.

As seções transversais foram aproximadas pelo formato trapezoidal, considerando-as simétricas e invariáveis ao longo do tempo (efeitos de erosão e sedimentação desconsiderados). $\mathrm{Na}$ Tabela 1 são indicadas as distâncias e a declividade entre os trechos, assim como a profundidade, vazão e largura do rio utilizadas na condição inicial.

A calibração do módulo hidrodinâmico foi realizada através do coeficiente de rugosidade de Manning, e para verificação da qualidade do ajuste foi utilizado o parâmetro de Nash-Sutcliffe. Na Tabela 2 são apresentados os valores obtidos.

As vazões simuladas e observadas nos cinco pontos de monitoramento para o ano de 2010 são comparadas na Figura 3. Os resultados mostram que o modelo simula adequadamente as oscilações de vazão no período considerado, com coeficientes de Nash-Sutcliffe variando de 0,80 no ponto IG 5 a 0,97 no ponto IG3.

A montante do ponto IG5 ocorre mudanças das características hidráulicas, uma vez que o rio passa a ter meandros. Como o modelo propaga informações de IG2 para jusante, essas modificações não são propriamente representadas. A variação de declividade do fundo do rio $\left(S_{0}\right)$, ou mesmo as curvas-chave utilizadas, podem contribuir para a superestimação de alguns picos, como observado principalmente no hidrograma da seção IG5.

\section{Modelagem de qualidade de água}

Em projetos que envolveram a caracterização do rio Iguaçu (PORTO et al., 2007; FERNANDES, 2013; KNAPIK, 2014), foram realizadas coletas de água nos anos de 2005 a 2013, com estimativas de vazão e medição de temperatura correspondentes. As amostras geraram dados de concentrações de DBO, OD, amônia e nitrito, entre outros parâmetros. Como para o ano de 2010 havia apenas entre quatro e cinco medições para essas variáveis, optou-se por utilizar em cada seção valores médios de amônia, nitrito e temperatura. Utilizou-se, ainda, uma concentração de oxigênio de saturação $\left(O_{s}\right)$ média, igual a $9,53 \mathrm{mgO} \cdot \mathrm{L}^{-1}$.

Ao longo do rio Iguaçu diversos afluentes contribuem para a alteração da vazão e da concentração de substâncias poluentes. As cargas orgânicas lançadas do canal principal foram estimadas com base nos dados de população de cada sub-bacia no ano de 2010, considerando apenas as contribuições domésticas, distribuídas de forma linear entre os trechos estudados. As cargas avaliadas para DBO foram: entre IG2 e IG3 - 7687,68 kg/dia; entre IG3 e IG4 - 11081,55 kg/dia; entre IG4 e IG5 - 617,77 kg/dia; entre 
Tabela 1. Características físicas dos pontos de monitoramento ( $y, U$ e $B$ : condições iniciais médias nos trechos).

\begin{tabular}{lccccc}
\hline \multicolumn{1}{c}{ Trecho } & Distância $(\mathbf{m})$ & $\boldsymbol{S}_{\boldsymbol{0}}(\mathbf{m} / \mathbf{m})$ & $\boldsymbol{y}(\mathbf{m})$ & $\boldsymbol{U}(\mathrm{m} / \mathbf{s})$ & $\boldsymbol{B}(\mathbf{m})$ \\
\hline IG2 a IG3 & 18175 & 0,00022 & 1,24 & 0,46 & 22,48 \\
IG3 a IG4 & 21855 & 0,00023 & 1,81 & 0,61 & 36,33 \\
IG4 a IG5 & 18256 & 0,00022 & 2,20 & 0,58 & 49,31 \\
IG5 a IG6 & 25443 & 0,00016 & 2,50 & 0,51 & 54,14 \\
Total & 83730 & & & & \\
\hline
\end{tabular}

IG3

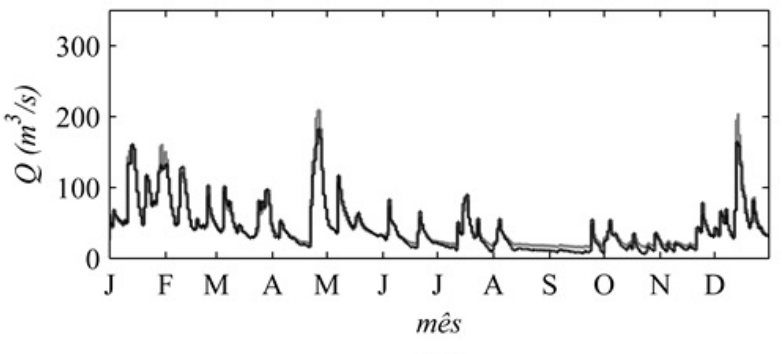

IG5

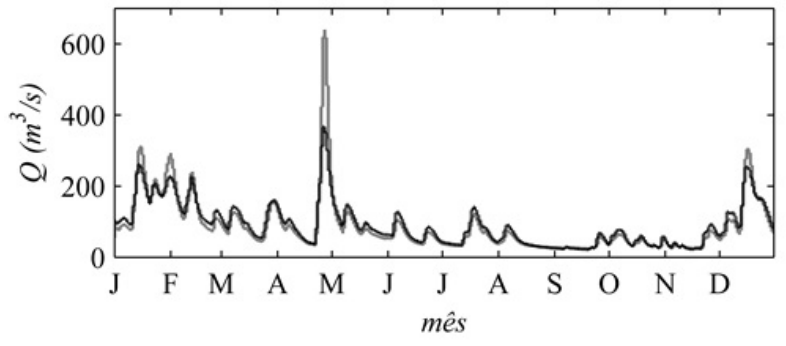

IG4

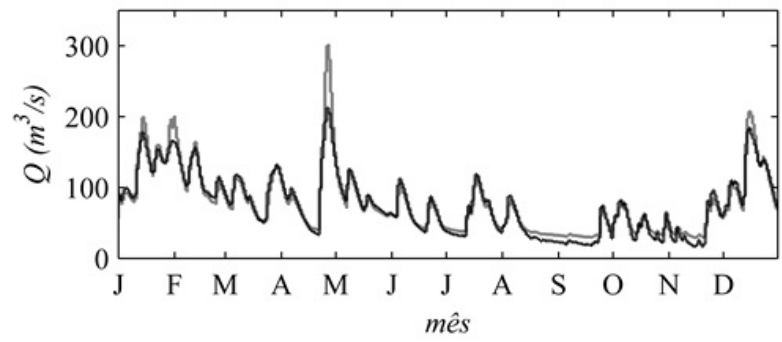

IG6

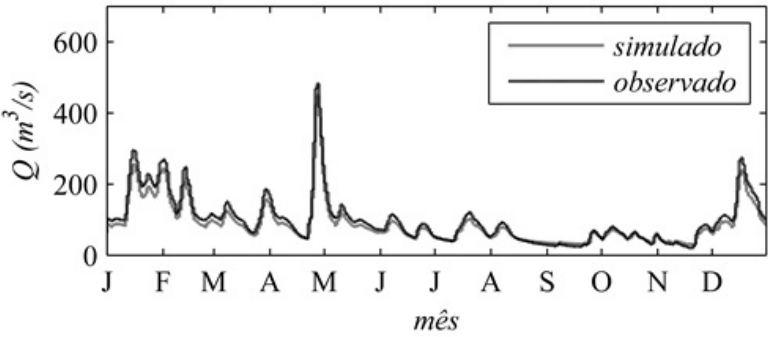

Figura 3. Vazões medidas e simuladas para 2010.

Tabela 2. Coeficientes de rugosidade de Manning calibrados e coeficientes de Nash-Sutcliffe para as simulações.

\begin{tabular}{|c|c|c|}
\hline Pontos & $\begin{array}{c}\text { Coeficiente } n \\
\left(\mathrm{~m}^{-1 / 3} \cdot \mathrm{s}\right)\end{array}$ & $\begin{array}{l}\text { Coeficientes de } \\
\text { Nash-Sutcliffe }\end{array}$ \\
\hline IG2 & 0,030 & - \\
\hline IG3 & 0,030 & 0,97 \\
\hline IG4 & 0,035 & 0,93 \\
\hline IG5 & 0,040 & 0,80 \\
\hline IG6 & 0,045 & 0,94 \\
\hline
\end{tabular}

IG5 e IG6 - 516,34 kg/dia. O detalhamento dos cálculos para obtenção desses valores é apresentado por Knapik et al. (2009).

A metodologia utilizada para a calibração dos modelos permanente e não-permanente segue exemplo do que foi realizado por Porto et al. (2007) e Knapik (2014) em simulação da qualidade da água para o rio Iguaçu com o modelo Qual2E. O procedimento consiste na combinação de valores de forma a reproduzir um cenário de concentração conhecido, representado pelo conjunto das observações de campo. Estes, por sua vez, foram organizados em gráficos do tipo box plot. O critério adotado considerou ajuste ótimo a combinação de parâmetros que gerou resultados mais próximos à mediana dos dados medidos em cada ponto.

Na Tabela 3 são apresentados os coeficientes de reação para DBO e OD calibrados. Os demais parâmetros estimados para todo o canal foram: $D=20 \mathrm{~m}^{2} \cdot \mathrm{s}^{-1} ; \alpha_{5}=3,5 \mathrm{mgO} \cdot \mathrm{mgN}^{-1}$; $\alpha_{6}=1,14 \mathrm{mgO}_{2} \cdot \mathrm{mgN}^{-1} ; \beta_{1}=0,12 \mathrm{~d}^{-1} ; \beta_{2}=1,0 \mathrm{~d}^{-1}$. O parâmetro $K_{a}$ foi obtido de diferentes formas nos modelos de estado estacionário e transiente, sendo discutido a seguir.

\section{Regime permanente}

As variações de velocidade e de área para regime permanente foram obtidas a partir das médias dos resultados gerados pela solução das equações de Saint-Venant, desprezando a variação temporal. Considerou-se que essa hipótese não gera resultados significantemente diferentes dos métodos usuais, com o uso da equação de Manning, por exemplo.

O modelo para OD se mostrou bastante sensível ao coeficiente $K_{a}$ durante os testes para calibração. Foi utilizada a equação de O'Connor e Dobbins para cálculo desse parâmetro, com valores apresentados na Tabela 3 .

As concentrações de DBO e OD simuladas em regime permanente para o rio Iguaçu são apresentadas nas Figuras 4 e 5, respectivamente, assim como os box plots gerados a partir dos dados coletados em campo de 2005 a 2013.

Os resultados mostram que o modelo simula a variação de concentração ao longo do rio de forma adequada, com valores relativamente próximos à mediana dos dados medidos. O decaimento da concentração, consequência das variações de entradas laterais, diluição e transformações cinéticas, é acompanhado pelo modelo. Nos pontos IG2 e IG3, a condição de contorno adotada pode ter 
Curvas de permanência de qualidade da água como subsídio para o enquadramento de corpos d'água a partir de modelagem matemática em regime não permanente

contribuído para que os valores de DBO simulados destoassem ligeiramente dos medidos.

As oscilações ao longo do rio, entretanto, não são reproduzidas, uma vez que a carga externa foi considerada distribuída uniformemente entre os trechos, e a advecção não varia no tempo. Entre os pontos IG2 e IG3, que recebem as maiores contribuições externas, a concentração de OD diminui devido a

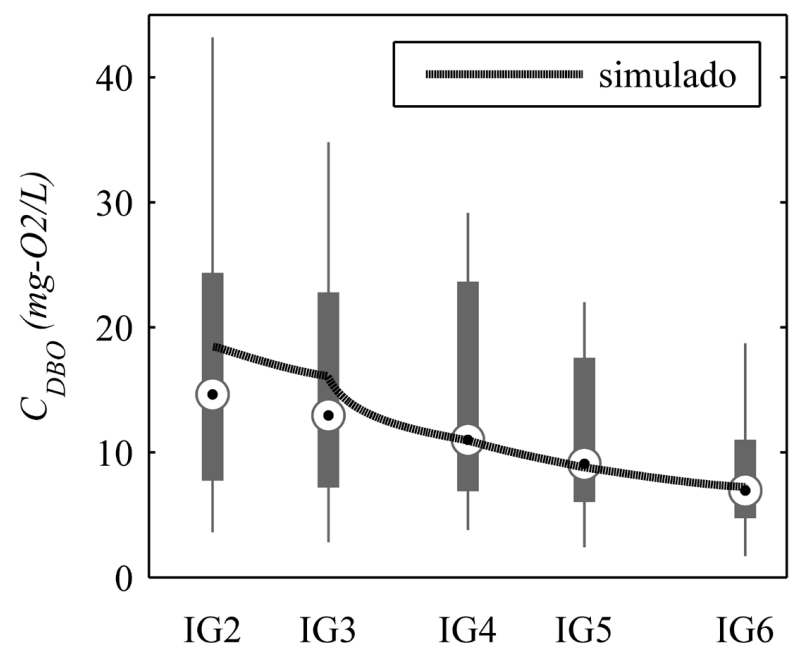

Figura 4. Simulação de concentração de DBO em regime permanente e dados medidos (Boxplot).

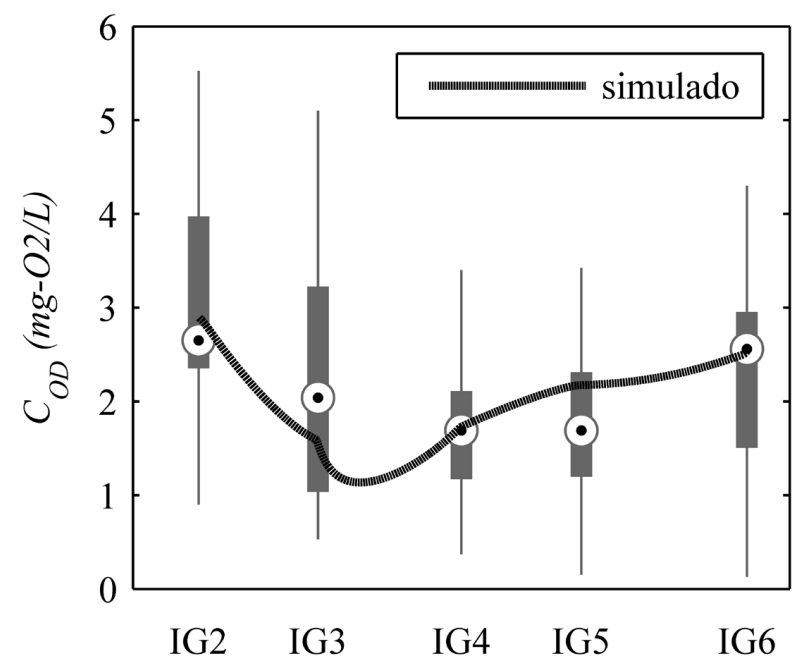

Figura 5. Simulação de concentração de OD em regime permanente e dados medidos (Boxplot). maior quantidade de matéria degradada. A partir do trecho entre IG3 e IG4 a reaeração promove aumento do oxigênio dissolvido disponível.

\section{Regime não-permanente}

Na simulação em regime não-permanente de OD os mesmos coeficientes de reaeração calculados para o modelo de estado permanente geraram resultados superestimados de concentração (mediana de dados simulados entre 3,3 e 4,3 $\mathrm{mgO}_{2} \cdot \mathrm{L}^{-1}$ maior que a mediana de valores obtidos em campo). Os autores Melching e Flores (1999) afirmam que, em condições de vazões de estiagem, a maioria dos corpos hídricos se comporta como uma sequência de poços e corredeiras, cujos valores de reaeração são altos. No modelo permanente, a vazão no rio variou de 9,61 a 82,23 $\mathrm{m}^{3} / \mathrm{s}$, com média de $45,09 \mathrm{~m}^{3} / \mathrm{s}$. Para o modelo não-permanente, por outro lado, essa variação ficou entre 2,54 e $450,86 \mathrm{~m}^{3} / \mathrm{s}$, com média de $62,32 \mathrm{~m}^{3} / \mathrm{s}$. Logo, valores mais altos de reaeração na simulação em estado permanente são justificados.

Diante disso, foram calibrados outros coeficientes de reaeração para o modelo não-permanente, apresentados anteriormente na Tabela 3. Ao verificar os valores, nota-se que o efeito da variação temporal interfere significativamente na determinação desse parâmetro; no ponto IG2, o $K_{a}$ utilizado para o modelo permanente é até oito vezes maior que no não-permanente.

A comparação entre box plots de dados medidos e simulados para estado transiente é apresentada nas Figuras 6 e 7. Observa-se que as medianas (utilizadas como parâmetro de calibração) ficaram relativamente próximas (diferença absoluta de 0,2768 $\mathrm{mgO} \cdot \mathrm{L}^{-1}$ em IG3 a 3,9281 mgO $\cdot \mathrm{L}^{-1} \mathrm{em} \mathrm{IG2}$ para DBO; 0,0166 mgO ${ }_{2} \cdot \mathrm{L}^{-1}$ em IG5 a $0,4610 \mathrm{mgO} \cdot \mathrm{L}^{-1} \mathrm{em} \mathrm{IG2}$ para OD).

Os dados de campo obtidos no ano de 2010 foram contrapostos com as concentrações médias diárias simuladas, como apresentado nas Figuras 8 e 9.

Para DBO, pode-se observar que os resultados do modelo ficam próximos dos dados medidos. No mês de agosto há um dado que diverge substancialmente da simulação. No período de agosto a outubro ocorreu um evento de estiagem, e outras interferentes não representadas na condição de contorno (efeito da variação temporal dos lançamentos sobre a concentração, por exemplo), podem ter contribuído para esse resultado discordante. Deve-se considerar, ainda, a já conhecida incerteza associada a questão das características analíticas de determinação da DBO, como descrito em APHA (1998).

Adicionalmente, como enfatizado por Porto et al. (2007), a relação entre vazão e concentração não segue uma tendência, uma vez que ambas variáveis dependem de uma série de condições,

Tabela 3. Coeficientes de reação utilizados nas simulações de qualidade de água.

\begin{tabular}{cccccc}
\hline Pontos & $\boldsymbol{K}_{\boldsymbol{d}}\left(\mathbf{d}^{-\mathbf{1}}\right)$ & $\boldsymbol{K}_{\boldsymbol{s}} \mathbf{( \mathbf { d } ^ { - 1 } )}$ & $\boldsymbol{K}_{\mathbf{4}}\left(\mathbf{g O}_{\mathbf{2}} \cdot \mathbf{m}^{-\mathbf{2}} \cdot \mathbf{d}^{-\mathbf{1}}\right)$ & $\boldsymbol{K}_{\boldsymbol{a}}{ }^{\mathrm{I}} \mathbf{( \mathbf { d } ^ { - 1 } )}$ & $\boldsymbol{K}_{\boldsymbol{a}}{ }^{\mathrm{II}}\left(\mathbf{d}^{-\mathbf{1}}\right)$ \\
\hline IG2 & 0,70 & 0,30 & 1,5 & 2,79 & 0,35 \\
IG3 & 0,70 & 0,30 & 1,5 & 1,67 & 0,35 \\
IG4 & 0,30 & 0,30 & 1,0 & 0,19 & 0,40 \\
IG5 & 0,20 & 0,15 & 0,5 & 0,80 & 0,45 \\
IG6 & 0,20 & 0,15 & 0,5 & 1,24 & 0,60 \\
\hline
\end{tabular}

I - calibrado no modelo de regime permanente. II - calibrado no modelo de regime não-permanente. 


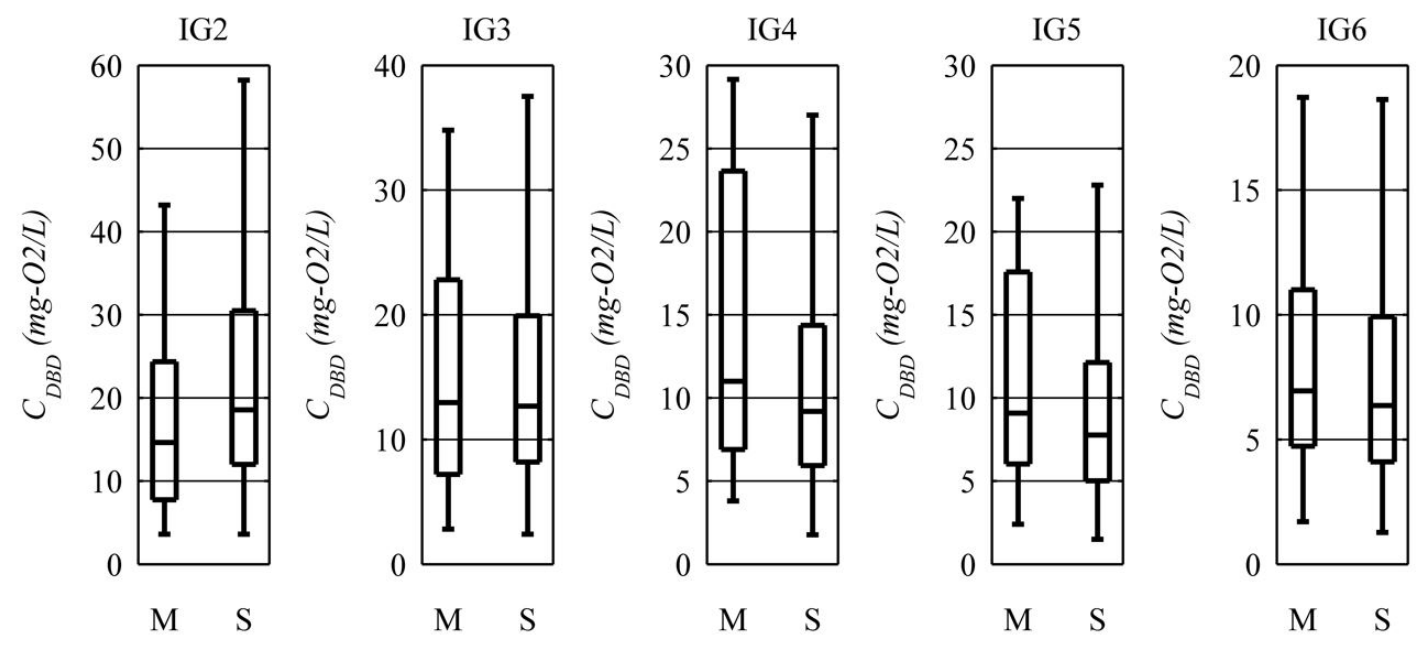

Figura 6. Boxplots medidos (M) e simulados (S) em regime não-permanente para DBO.
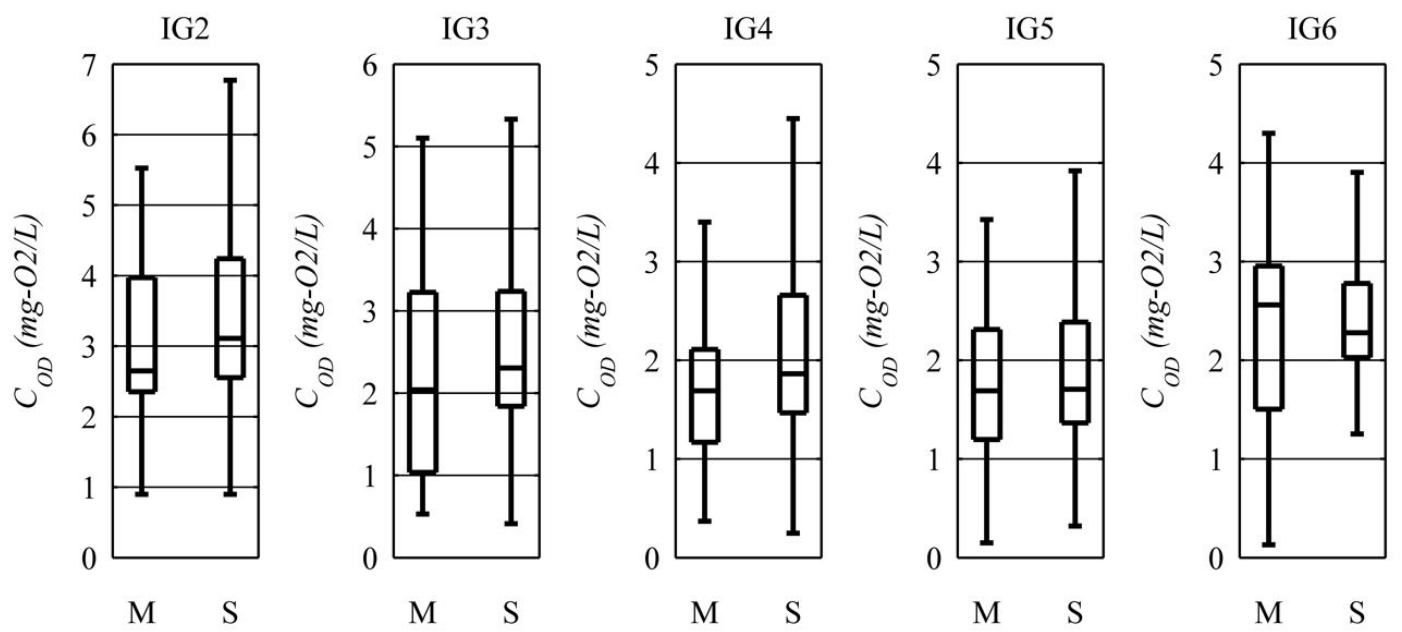

Figura 7. Box plots medidos (M) e simulados (S) em regime não-permanente para OD.

como regime pluviométrico e uso do solo na bacia. Entretanto, devido à representação da condição de contorno e à consideração de cargas afluentes distribuídas de forma linear ao longo do tempo e espaço, neste trabalho não foi possível representar essa dinâmica, prejudicando a simulação de eventos críticos, principalmente. Dentro deste contexto, o modelo em regime não permanente mostrou-se mais robusto para concentrações baixas do que as elevadas, suscitando um interessante desafio de compatibilizar os dados simulados considerando as incertezas relativas aos parâmetros de qualidade da água medidos.

Na simulação do oxigênio dissolvido, apesar de a mediana simulada ficar próxima da medida (como verificado na Figura 7), vários pontos medidos ficam distantes da linha de valores simulados. O oxigênio é um constituinte complexo a ser simulado em modelagem de qualidade de água, uma vez que sua distribuição é afetada por diversos processos químicos, físicos e biológicos (concentração de DBO, amonificação, nitrificação, reaeração, profundidade e velocidade do canal etc). Segundo Mannina e Viviani (2010), uma ligeira diferença nos cálculos desses processos pode contribuir para o desacordo entre valores medidos e simulados das concentrações de oxigênio.

\section{Curvas de permanência}

A partir dos resultados obtidos com o modelo hidrodinâmico, foram obtidas as vazões correspondentes a 20, 30, 40, 50, 60, 70, 80, 90 e 95\% de permanência para os pontos IG2 a IG6. No modelo de qualidade de água em condição permanente, essas vazões foram usadas para cálculo das velocidades de escoamento correspondentes em cada ponto. A profundidade do escoamento, entretanto, não foi corrigida para essas novas vazões. Com exceção do coeficiente $K_{a}$ no modelo para OD, que depende da velocidade em sua formulação, os demais parâmetros calibrados não foram alterados nessas análises.

Associando a permanência das vazões à permanência de concentrações, e a partir das considerações descritas, foram geradas as curvas de frequência com o modelo em regime permanente, representadas nas Figuras 10 e 11. A curva de permanência para estado não-permanente, representada pela linha contínua nas mesmas figuras, foi gerada através da disposição das concentrações simuladas em ordem decrescente e cálculo das frequências acumuladas. Nos mesmos gráficos também são apresentadas as 

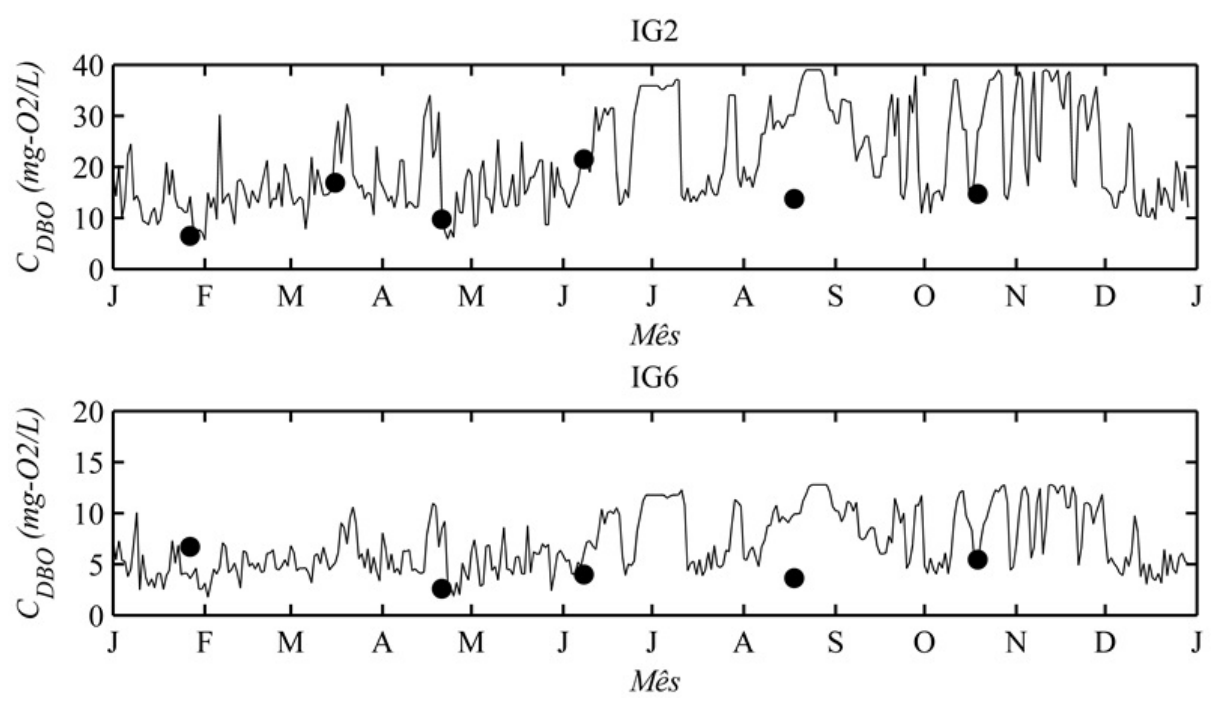

Figura 8. Concentrações médias diárias simuladas (linha contínua) e medições (pontos) de DBO no ano de 2010.
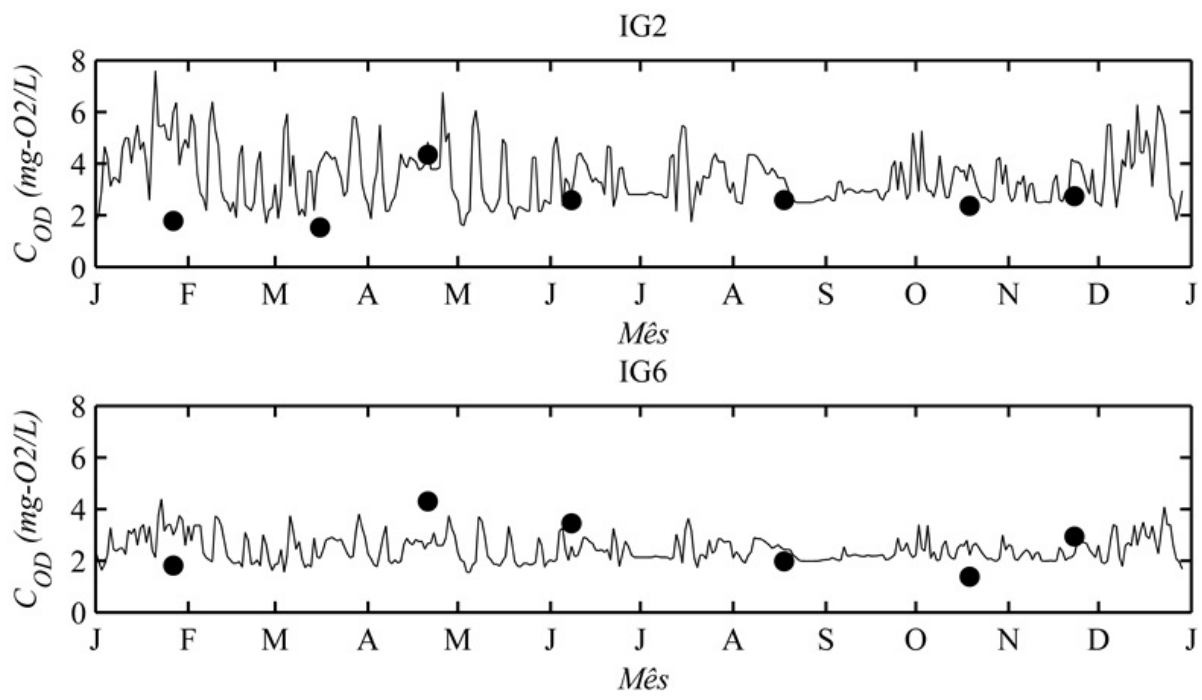

Figura 9. Concentrações médias diárias simuladas (linha contínua) e medições (pontos) de OD no ano de 2010.
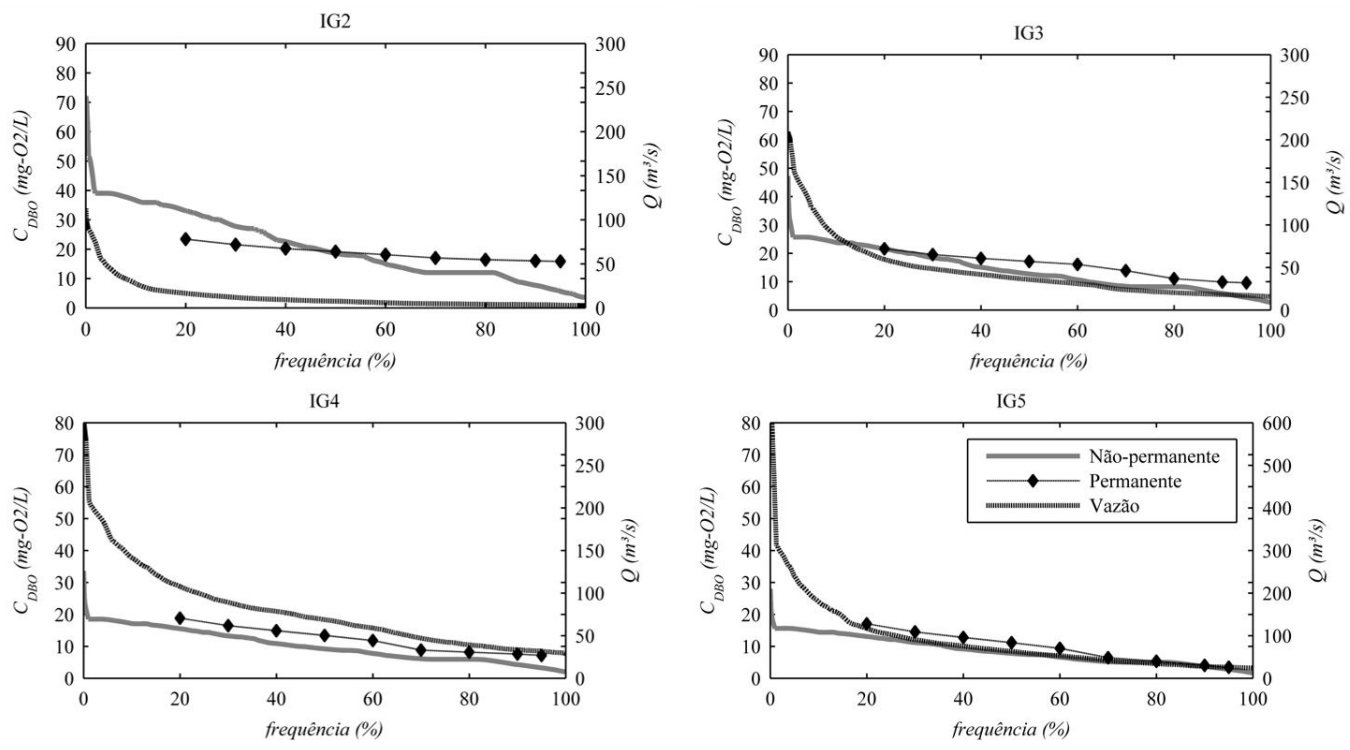

Figura 10. Curvas de permanência para DBO geradas com o modelo não-permanente e permanente. 

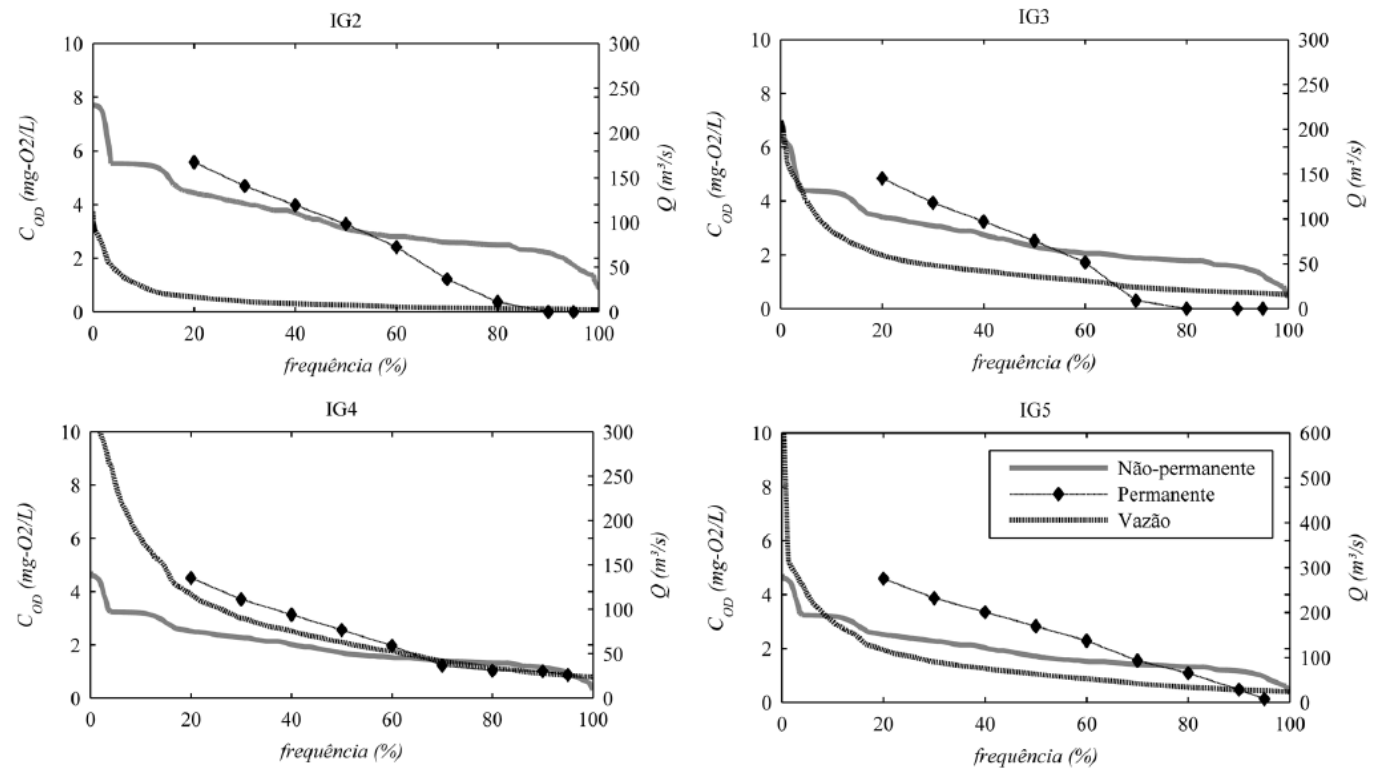

Figura 11. Curvas de permanência para OD geradas com o modelo não-permanente e permanente.

curvas de permanência das vazões calculadas com as equações de Saint-Venant.

Para DBO, no ponto IG5 principalmente, as concentrações do modelo permanente de 95 a $80 \%$ de permanência tendem a se aproximar dos valores gerados pelo modelo não-permanente, e divergirem para as frequências menores. Nessa região, onde a qualidade da água é ligeiramente melhor, os modelos permanente e não-permanente geraram resultados similares em condições de baixas vazões; ao atingir condições de maiores vazões (que correspondem também a concentrações mais altas), as discrepâncias entre os resultados aumentam.

Para trechos menos impactados, com melhor qualidade de água, e em condições de vazões mais baixas, as variações de concentração são mais lentas, confirmando o que foi apontado por Garcia e Tucci (2000). Ao aumentar a vazão, o papel da advecção torna-se mais importante sobre a distribuição de massa, além de ocorrer aumento da carga difusa que chega ao rio devido ao escoamento superficial. Por outro lado, no trecho de IG2 a IG3, onde a poluição por fontes externas é maior, a dinâmica do sistema faz com que essa relação concentração-vazão seja mais irregular.

No ponto IG2 ocorreram as maiores discrepâncias de concentração para cada frequência geradas pelo modelo de regime permanente e pelo não-permanente (diferença absoluta 0,56 a 10,16 mgO ${ }_{2} \cdot \mathrm{L}^{-1}$ ), identificando os efeitos da definição das diferentes condições de contorno.

Para um dado valor de concentração, observa-se ainda que a maioria das frequências de ocorrência para o modelo permanente é maior que para o não-permanente. Como exemplo, a Tabela 4 apresenta essa relação para uma concentração de $10 \mathrm{mgO}_{2} \cdot \mathrm{L}^{-1} \mathrm{de}$ $\mathrm{DBO}$ e $2 \mathrm{mgO}_{2} \cdot \mathrm{L}^{-1}$ de OD. Em alguns casos as diferenças são maiores que $20 \%$, indicando que o modelo permanente tende a superestimar o tempo de permanência do rio em diferentes classes ao longo do ano.

Dessa forma, a definição mais acurada da vazão pode ser importante para determinados propósitos. Diferenças de
Tabela 4. Frequências de ocorrência para $10 \mathrm{mgO}$. $\mathrm{L}^{-1}$ de DBO e $2 \mathrm{mgO}_{2} \cdot \mathrm{L}^{-1}$ de OD obtidas com os modelos permanente $(\mathrm{P}) \mathrm{e}$ não-permanente (NP).

\begin{tabular}{cccccc}
\hline \multirow{2}{*}{ Ponto } & \multicolumn{2}{c}{ DBO } & & \multicolumn{2}{c}{ OD } \\
\cline { 2 - 3 } \cline { 5 - 6 } & $\mathbf{P}$ & $\mathbf{N P}$ & & $\mathbf{P}$ & NP \\
\hline IG3 & $89 \%$ & $62 \%$ & & $56 \%$ & $65 \%$ \\
IG4 & $66 \%$ & $44 \%$ & & $60 \%$ & $46 \%$ \\
IG5 & $56 \%$ & $36 \%$ & & $64 \%$ & $41 \%$ \\
\hline
\end{tabular}

$1 \mathrm{mgO} \cdot \mathrm{L}^{-1}$ para OD, por exemplo, são suficientes para mudar a classificação de enquadramento do trecho estudado, e impactar decisões para planos de ação em bacias hidrográficas urbanizadas. Mais especificamente, fica evidente que a forma de se caracterizar a dinâmica do rio é relevante para a definição da curva de permanência de qualidade da água.

\section{CONCLUSÕES}

A implementação dos instrumentos de gestão de recursos hídricos no tocante ao estabelecido pela Lei 9.433/97 é uma questão de caráter conceitual e técnico. Ela necessita ser explorada à luz de uma combinação entre dados consistente e ferramentas computacionais que permitam estabelecer condições para regras justas de gestão, com base em uma adequada reprodução da realidade física, química e biológica. As análises realizadas neste trabalho buscaram contribuir para a construção de ferramentas apropriadas para a interpretação dessas questões.

A combinação dos esquemas difusivo de Lax com o FTCS gerou resultados consistentes e estáveis ao longo da simulação estendida temporalmente. A associação de métodos explícitos, pouco usual em trabalhos semelhantes, mostrou-se eficiente na solução das equações de Saint-Venant e de transporte de massa, demonstrando a possibilidade de se obter soluções numéricas mais simples em problemas unidimensionais de qualidade da água. 
Curvas de permanência de qualidade da água como subsídio para o enquadramento de corpos d'água a partir de modelagem matemática em regime não permanente

$\mathrm{Na}$ fase de calibração do modelo de qualidade de água, foi verificado que a variação da velocidade de escoamento tem influência direta sobre o coeficiente de reaeração. Diante disso, fica evidente a necessidade de se analisar com cautela aspectos relativos a parâmetros de reação na modelagem. O uso de um determinado conjunto de valores pode, por exemplo, sobrepor os efeitos reais de transporte sobre a distribuição de poluentes em rios. Nesse caso, medidas de despoluição, por exemplo, podem ser mais onerosas do que o necessário, ou ter sua eficiência comprometida.

Nas simulações em condição não-permanente foram obtidos valores de demanda bioquímica de oxigênio mais próximos das concentrações obtidas em campo do que para oxigênio dissolvido. Isso ocorreu principalmente porque a DBO leva em consideração apenas dois parâmetros de reação $\left(K_{d}\right.$ e $\left.K_{S}\right)$, enquanto a previsão de OD é afetada por diversos outros fatores (como temperatura e concentração de amônia e nitrito), representadas de modo simplificado nessa pesquisa. Embora tenham sido obtidos resultados dentro da faixa de aceitação, recomenda-se que os efeitos desses outros interferentes sejam investigados em estudos futuros, uma vez que a previsão de OD usualmente é a razão primária para o desenvolvimento de modelos de qualidade de água.

Outra questão relevante, e que deve ser explorada em trabalhos futuros, refere-se a erros devido a difusão numérica. Segundo Szymkiewicz (2010), quando o transporte de uma substância é dominado pela difusão, o método de diferenças finitas e o de elementos finitos geram resultados satisfatórios na solução da equação para simulação de qualidade de água. No entanto, se o processo de advecção é dominante, espera-se que ocorram oscilações e difusão numérica. Para Raithby (1976), na maioria dos métodos essas oscilações podem ser evitadas através da inclusão de uma difusão artificial, introduzida explicitamente nas equações governantes ou gerada pelo próprio método.

A relação entre os aspectos de quantidade e qualidade de água, estabelecida através da curva de permanência, tem aplicações potenciais na gestão de recursos hídricos, em particular sobre os instrumentos definidos na Lei 9.433 .

A comparação do comportamento dessas curvas utilizando a abordagem da modelagem em estado permanente e não-permanente foi significativa o suficiente para destacar o impacto de um melhor detalhamento temporal da base de dados de qualidade da água, quando se compara com a forma atual de monitoramento e modelagem do ponto de vista computacional.

Com as análises desenvolvidas foi possível avançar no entendimento acerca do comportamento hidrológico e da variação da concentração de DBO e OD ao longo do rio Iguaçu, mesmo a partir de poucos dados de campo.

\section{REFERÊNCIAS}

ALMEIDA, C. C.; FERNANDES, C. V. S.; KNAPIK, H. G.; SIECIECHOWICZ, M. S. F. Análise comparativa e estatística entre carga e concentração no monitoramento da qualidade da água em rios urbanos. In: SIMPÓSIO BRASILEIRO DE RECURSOS HÍDRICOS, 20., 2013, Bento Gonçalves. Porto Alegre: ABRH, 2013.
APHA - AMERICAN PUBLIC HEALTH ASSOCIATION. Standard methods for the examination of water and wastewater. 20. ed. Washington, 1998.

ATKINSON, J. F.; GUPTA, S. K.; DEPINTO, J. V.; RUMER, R. R. Linking hydrodynamic and water quality models with different scales. Journal of Environmental Engineering, v. 124, n. 5, p. 399-408, 1998. http://dx.doi.org/10.1061/(ASCE)0733-9372(1998)124:5(399).

BABBAR, R. Pollution risk assessment based on QUAL2E-UNCAS simulations of a tropical river in Northern India. Environmental Monitoring and Assessment, v. 186, n. 10, p. 6771-6787, 2014. http:// dx.doi.org/10.1007/s10661-014-3888-1. PMid:24990347.

BEDRI, Z.; CORKERY, A.; O'SULLIVAN, J. J.; ALVAREZ, M. X.; ERICHSEN, A. C.; DEERING, L. A.; DEMETER, K.; O'HARE, G. M. P.; MEIJER, W. G.; MASTERSON, B. An integrated catchment-coastal modelling system for real-time water quality forecasts. Environmental Modelling \& Software, v. 61, p. 458-476, 2014. http://dx.doi.org/10.1016/j.envsoft.2014.02.006.

BOWIE, G. L.; MILLS, W. B.; PORCELLA, D. B. Rates, constants, and kinetics formulations in surface water quality modeling. 2. ed. California: Environmental Protection Agency, 1985.

BOYE, B. A.; FALCONER, R. A.; AKANDE, K. Integrated water quality modelling: application to the Ribble Basin, U.K. Journal of Hydro-environment Research, v. 9, n. 2, p. 187-199, 2015. http://dx.doi.org/10.1016/j.jher.2014.07.002.

BRASIL. Lei Federal no 9.433, de 8 de janeiro de 1997. Institui a Política Nacional de Recursos Hídricos, cria o Sistema Nacional de Gerenciamento de Recursos Hídricos, regulamenta o inciso XIX do art. 21 da Constituição Federal, e altera o art. $1^{\circ}$ da Lei $\mathrm{n}^{\mathrm{o}}$ 8.001, de 13 de março de 1990, que modificou a Lei $\mathrm{n}^{\circ} 7.990$, de 28 de dezembro de 1989. Diário Oficial da União, Brasília, DF, 8 jan. 1997.

BRASIL. Conselho Nacional do Meio Ambiente - CONAMA. Resolução n 357, de 17 de março de 2005. Estabelece a classificação das águas doces, salobras e salinas do Território Nacional. Diário Oficial da União, Brasília, DF, 18 mar., 2005.

BRITES, A. P. Z. Enquadramento dos corpos de água através de metas progressivas: probabilidade de ocorrência e custos de despoluição hídrica. 2010. 205 f. Tese (Doutorado em Engenharia) - Universidade de São Paulo, São Paulo, 2010.

BROWN, L. C.; BARNWELL, T. O. The enhanced stream water quality model QUAL2E and QUAL2E-UNCAS: computer program documentation and user manual. Athens: United States Environmental Protection Agency, 1987. 189 p.

CHAPRA, S. C. Surface water-quality modeling. Boston: WCB/ McGraw-Hill, 1997.

COELHO, M. Estratégia de monitoramento de qualidade da água para gestão recursos hídricos em bacias urbanas. 2013. 147 f. Dissertação 
(Mestrado em Engenharia de Recursos Hídricos e Ambiental) Universidade Federal do Paraná, Curitiba, 2013.

CUNHA, D. G. F.; CALIJURI, M. C. Análise probabilística de ocorrência de incompatibilidade da qualidade da água com o enquadramento legal de sistemas aquáticos: estudo de caso do rio Pariquera-Açu (SP). Engenharia Sanitária e Ambiental, v. 15, n. 4, p. 337-346, 2010. http://dx.doi.org/10.1590/S141341522010000400006.

CUNHA, D. G. F.; CALIJURI, M. C.; MENDIONDO, E. M. Integração entre curvas de permanência de quantidade e qualidade da água como uma ferramenta para a gestão eficiente dos recursos hídricos. Engenharia Sanitária e Ambiental, v. 17, n. 4, p. 369-376, 2012. http://dx.doi.org/10.1590/S1413-41522012000400003.

CUNHA, D. G. F.; GRULL, D.; DAMATO, M.; BLUM, J. R.; LUTTI, J. E.; EIGER, S.; MANCUSO, P. C. Trophic state evolution in a subtropical reservoir over 34 years in response to different management procedures. Water Science and Technology, v. 64, n. 12, p. 2338-2344, 2011. http://dx.doi.org/10.2166/wst.2011.826. PMid:22170825.

DORTCH, M.; JOHNSON, B. Hydrodynamics for water quality models. Baltimore: Hydraulic Engineering Sessions at Water Forum, American Society of Civil Engineers, 1992.

FAN, F. M.; COLLISCHONN, W.; RIGO, D. Modelo analítico de qualidade da água acoplado com Sistema de Informação Geográfica para simulação de lançamentos com duração variada. Engenharia Sanitária e Ambiental, v. 18, n. 4, p. 359-370, 2013. http://dx.doi. org/10.1590/S1413-41522013000400008.

FERNANDES, C. V. S. INTEGRA 2: bases técnicas para a integração de instrumentos de gestão de recursos hídricos: estudo de caso da Bacia do Alto Iguaçu e Bacia do Alto Tietê. Curitiba: Universidade Federal do Paraná, 2013.

FERREIRA, D. M. Simulação bidrodinâmica e de qualidade da água em rios: impacto para os instrumentos de gestão de recursos hídricos. 2015. 122 f. Dissertação (Mestrado em Engenharia de Recursos Hídricos e Ambiental) - Universidade Federal do Paraná, Curitiba, 2015.

FRITSCH, F. N.; CARLSON, R. E. Piecewise cubic interpolation methods. Grove City: U.S. Department of Energy, 1978.

GARCIA, R. L.; TUCCI, C. E. M. Simulação da qualidade da água em rios em regime não-permanente: Rio dos Sinos. Recursos Hidricos, v. 21, n. 2, p. 17-26, 2000.

HARTNETT, M.; NASH, S. An integrated measurement and modeling methodology for estuarine water quality management. Water Science and Engineering, v. 8, n. 1, p. 9-19, 2015. http:/ /dx.doi. org/10.1016/j.wse.2014.10.001.

HIRSCH, C. Numerical computation of internal and external flows. New York: Wiley, 1991.
KNAPIK, H. G. Organic matter characterization and modeling in polluted rivers for water quality planning and management. 2014. 281 f. Tese (Doutorado em Engenharia de Recursos Hídricos e Ambiental) - Universidade Federal do Paraná, 2014.

KNAPIK, H. G.; FRANCA, M. S.; FERNANDES, C. V. S.; AZEVEDO, J. C. R.; PORTO, M. F. A. Reflections about water quality recovery based upon conceptual aspects of monitoring and modeling organic content: the case study of a critical basin. IAHS-AISH Publication, v. 331, p. 358-365, 2009.

LARENTIS, D. G.; COLLISCHONN, W.; TUCCI, C. E. M. Simulação da qualidade de água em grandes bacias: Rio TaquariAntas, RS. Revista Brasileira de Recursos Hídricos, v. 13, n. 3, p. 5-22, 2008. http://dx.doi.org/10.21168/rbrh.v13n3.p5-22.

LI, N.; KINZELBACH, W.; LI, W.; DONG, X. Box model and 1D longitudinal model of flow and transport in Bosten Lake, China. Journal of Hydrology, v. 524, p. 62-71, 2015. http://dx.doi. org/10.1016/j.jhydrol.2015.02.032.

MAHMOOD, K.; V. YEVJEVICH. Unsteady flow in open channels. Fort Collins: Water Resources Publications, 1975.

MANNINA, G.; VIVIANI, G. River water quality assessment: a hydrodynamic water quality model for propagation of pollutants. Water Science and Technology, v. 62, n. 2, p. 288-299, 2010. http:// dx.doi.org/10.2166/wst.2010.285. PMid:20651432.

MELCHING, C. S.; FLORES, H. E. Reaeration equations derived from u.s. geological survey database. Journal of Environmental Engineering, v. 125, n. 5, p. 407-414, 1999. http://dx.doi.org/10.1061/ (ASCE)0733-9372(1999)125:5(407).

NAJAFI, H. S. Solving one-dimensional advection-dispersion with reaction using some finite-difference methods. The Mathematical Sciences, v. 2, n. 53, p. 2611-2618, 2008.

OLIVEIRA, P. T. S.; RODRIGUES, D. B. B.; SOBRINHO, T. A.; PANACHUKI, E. Integração de informações quali-quantitativas como ferramenta de gerenciamento de recursos hídricos. Revista de Estudos Ambientais, v. 13, n. 1, p. 18-27, 2011.

PARMAR, D. L.; KESHARI, A. K. Sensitivity analysis of water quality for Delhi stretch of the River Yamuna, India. Environmental Monitoring and Assessment, v. 184, n. 3, p. 1487-1508, 2012. http:// dx.doi.org/10.1007/s10661-011-2055-1. PMid:21544505.

PATOWARY, S.; SARMA, A. K. Hydrodynamic flood routing considering piedmont zone. International Journal of Civil and Structural Engineering, v. 3, p. 464-474, 2013.

PORTO, M. F. A.; FERNANDES, C. V. S.; KNAPIK, H. G.; FRANÇA, M. S.; BRITES, A. P. Z.; MARIN, M. C. F. C.; MACHADO, F. W.; CHELLA, M. R.; SÁ, J. F.; MASINI, L. Bacias críticas: bases técnicas para a definição de metas progressivas para seu enquadramento e a integração com os demais instrumentos 
de gestão. Curitiba: Universidade Federal do Paraná, FINEP/ CT-HIDRO, 2007.

RAITHBY, G. D. A critical evaluation of upstream differencing applied to problems involving fluid flow. Computer Methods in Applied Mechanics and Engineering, v. 9, n. 9, p. 75-103, 1976. http://dx.doi. org/10.1016/0045-7825(76)90078-5.

ROCHA, P. A. C.; PITOMBEIRA, E. Aplicação de método espectral em grade não-uniforme na avaliação de dispersão de poluentes no rio Cocó em Fortaleza-CE. Revista Brasileira de Recursos Hidricos, v. 18, n. 1, p. 53-65, 2013. http://dx.doi.org/10.21168/ rbrh.v18n1.p53-65.

SORRIBAS, M. V.; COLLISCHONN, W.; MARQUES, D.; FRAGOSO JÚNIOR, C.; CASTRO, N.; SOUZA, R. Modelagem distribuída do carbono em bacias hidrográficas. Revista Brasileira de Recursos Hídricos, v. 17, n. 3, p. 225-240, 2012. http://dx.doi. org/10.21168/rbrh.v17n3.p225-240.

SZYMKIEWICZ, R. Numerical modelling in open channel hydraulics. Dordrecht: Springer, 2010.

TANNEHILL, J.; ANDERSON, D.; PLETCHER, R. Computational fluid mechanics and heat transfer. 2. ed. New York: Hemisphere Publishing Corporation, 1997.

ZHANG, W.; ARHONDITSIS, G. B. Predicting the frequency of water quality standard violations using bayesian calibration of eutrophication models. Journal of Great Lakes Research, v. 34, n. 4, p. 698-720, 2008. http://dx.doi.org/10.1016/S0380-1330(08)71612-5.

\section{Contribuição dos autores}

Danieli Mara Ferreira: redação e formatação do texto, implementação das soluções que geraram os resultados apresentados (avaliação de dados, discretização das equações, escrita em código Matlab, definições de condições de contorno e inicial, definição dos intervalos espacial e temporal, calibração, consecução dos gráficos e figuras com resultados).

Cristovão Vicente Scapulatempo Fernandes: orientação do trabalho, correção do texto, consecução inicial do problema principal (resolução do problema de qualidade de água em regime não-permanente através das soluções de Saint-Venant e de transporte de poluentes); orientação da análise de resultados (curva de permanência).

Eloy Kaviski: co-orientação do trabalho, correção do texto, sugeriu o método difusivo de Lax a ser aplicado na solução das equações de Saint-Venant e a forma de avaliação da contribuição lateral; sugeriu as condições de contorno a serem utilizadas na solução do problema permanente e auxiliou sua implementação computacional. 